\title{
Calcinosis of the hand in scleroderma: A case report
}

\author{
Michael W Neumeister MD FRCSC ${ }^{1}$, Kenneth A Murray MD FRCSC FACS ${ }^{2}$ \\ ${ }^{1}$ Institute for Plastic \& Reconstructive Surgery, Southern Illinois University School of Medicine, \\ Springfield, Illinois, USA, ${ }^{2}$ Division of Plastic Surgery, University of Manitoba, Winnipeg, Manitoba
}

\section{MW Neumeister, KA Murray. Calcinosis of the hand in scleroderma: A case report. Can J Plast Surg 1999;7(5):241-244.}

Calcinosis associated with scleroderma is a well recognized phenomenon. Fifteen to $44 \%$ of patients with systemic scleroderma and associated CREST (calcifications, raynaud's phenomenon, esophageal motility disorder, sclerodactyly and telangiectasias) syndrome have deposition of calcium in the fingers and hands. The tumourous effect may limit motion, cause neuropraxia, compound microangiopathy or present as calcific ulcers. This report describes the case of a patient with scleroderma and CREST syndrome in whom calcinosis in the hand resulted in severe, debilitating pain necessitating surgical evacuation of the deposits. The patient had complete pain relief in the postopertive period. A further surgical extirpation of calcium was required for recurring pain at six months after surgery. The patient has remained symptom free since that time. The rare occurence of excruciating pain prompted this report and literature review.

Key Words: Calcinosis; CREST syndrome; Pain

\section{Calcinose de la main dans la sclérodermie : un rapport de cas}

RÉSUMÉ : Une calcinose associée à la sclérodermie est un phénomène connu. De $15 \%$ à $44 \%$ des patients atteints d'une sclérodermie généralisée et associée à un syndrome CREST (calcifications, phénomène de Raynaud, troubles de la motilité œesophagienne, sclérodactylie et télangiectasies) ont des dépôts de calcium dans les doigts et dans les mains. L'effet de masse peut limiter le mouvement, causer de la neuropraxie, une microangiopathie composée ou se présentant comme des ulcères calcifiés. Le présent rapport décrit le cas d'un patient atteint d'une sclérodermie et d'un syndrome CREST chez lequel une calcinose de la main a entraîné une douleur sévère et handicapante nécessitant une évacuation des dépôts de calcium par voie chirurgicale. L'intervention chirurgicale a permis un soulagement complet de la douleur. Une nouvelle intervention chirurgicale visant à extirper le calcium a été rendue nécessaire six mois après la première chirurgie en raison de la récurrence de la douleur. Depuis, le patient est resté asymptomatique. Ce cas rare de douleur extrême a incité la rédaction de ce rapport et la présente revue de la littérature.

$\mathrm{C}$ alcinosis associated with scleroderma is a wellrecognized phenomenon. Of the patients with systemic scleroderma and associated CREST (calcifications, raynaud's phenomenon, esophageal motility disorder, sclerodactyl and telangiectasias) syndrome, $15 \%$ to $44 \%$ have deposition of calcium in the fingers and hands $(1,2)$. Most patients are relatively symptom free when presenting with this calcinosis, but occasionally the tumourous effect may limit motion, cause neuropraxia, compound microangiopathy, present as calcific ulcers or incite pain. The case of a patient with scleroderma and CREST syndrome in whom

Correspondence: Dr Michael W Neumeister, Institute for Plastic and Reconstructive Surgery, Southern Illinois University School of Medicine, 747 North Rutledge, PO Box 19653, Springfield, Illinois 62794-9653, USA. Telephone 217-524-6314, fax 217-524-2588 calcinosis in the hand resulted in severe, debilitating pain necessitating surgical evacuation of the deposits is reported. The calcium was intimately associated with the extensor tendons on the dorsum of the hand. Digital involvement was also symptomatic. The rare occurrence of excruciating pain prompted this report and literature review.

\section{CASE PRESENTATION}

A 32-year-old man presented with a four-year history of diagnosed scleroderma and CREST syndrome. Calcinosis was present in both hands. He remained asymptomatic until the past six months when he experienced progressive pain in the dorsum of the left hand. Calcium channel blockers, Dpeniciliamine, anti-inflammatories and local analgesics were moderated by the rheumatologist. The patient's 


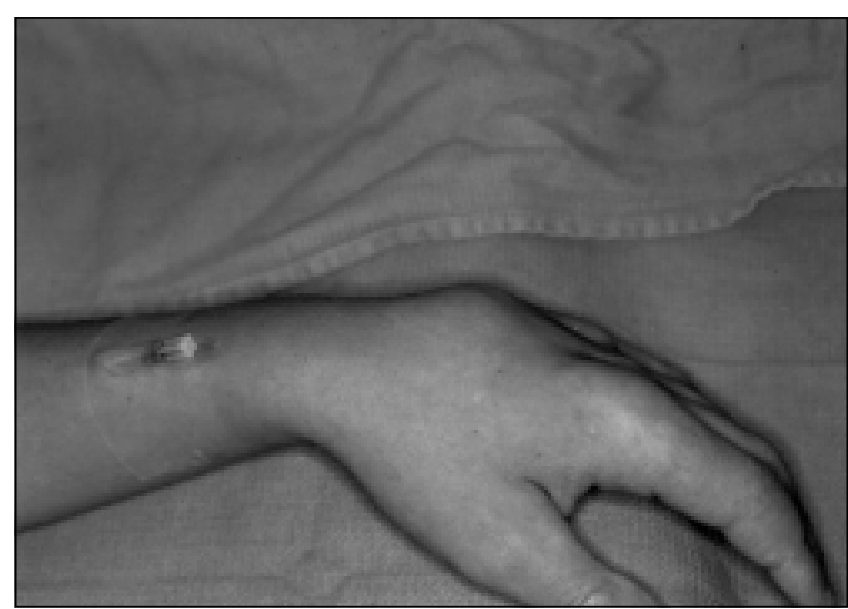

Figure 1) Mass on dorsum of left hand. The mass was tender, firm and stationary, and there was swelling at the metacarpal phalangeal joint of the index finger
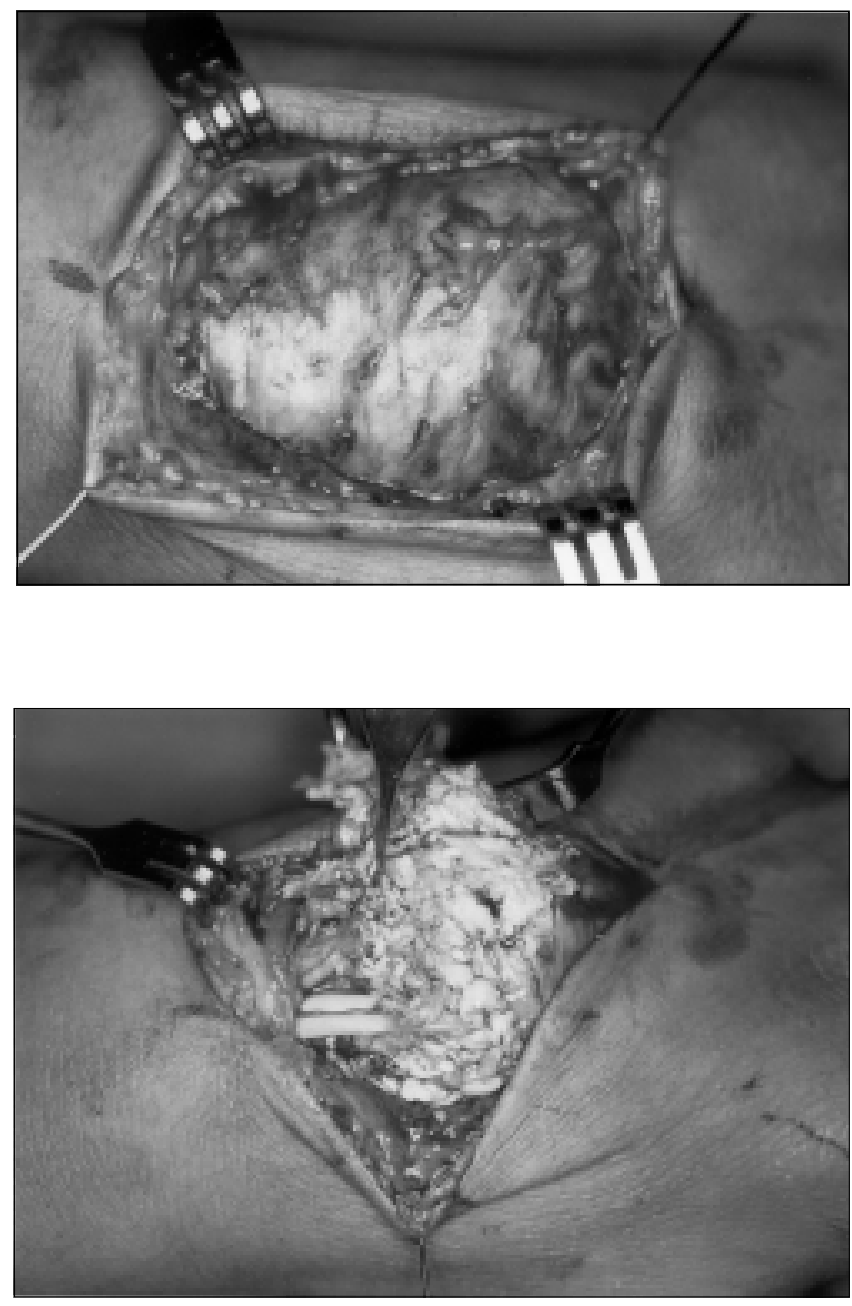

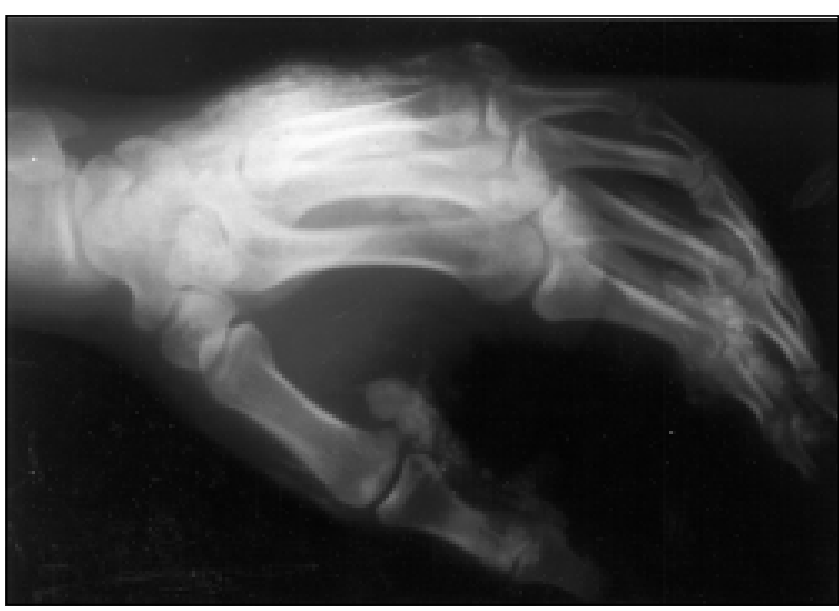

Figure 2) Left hand radiograph. The calcium deposits are noted on the dorsum of the hand and into the digits
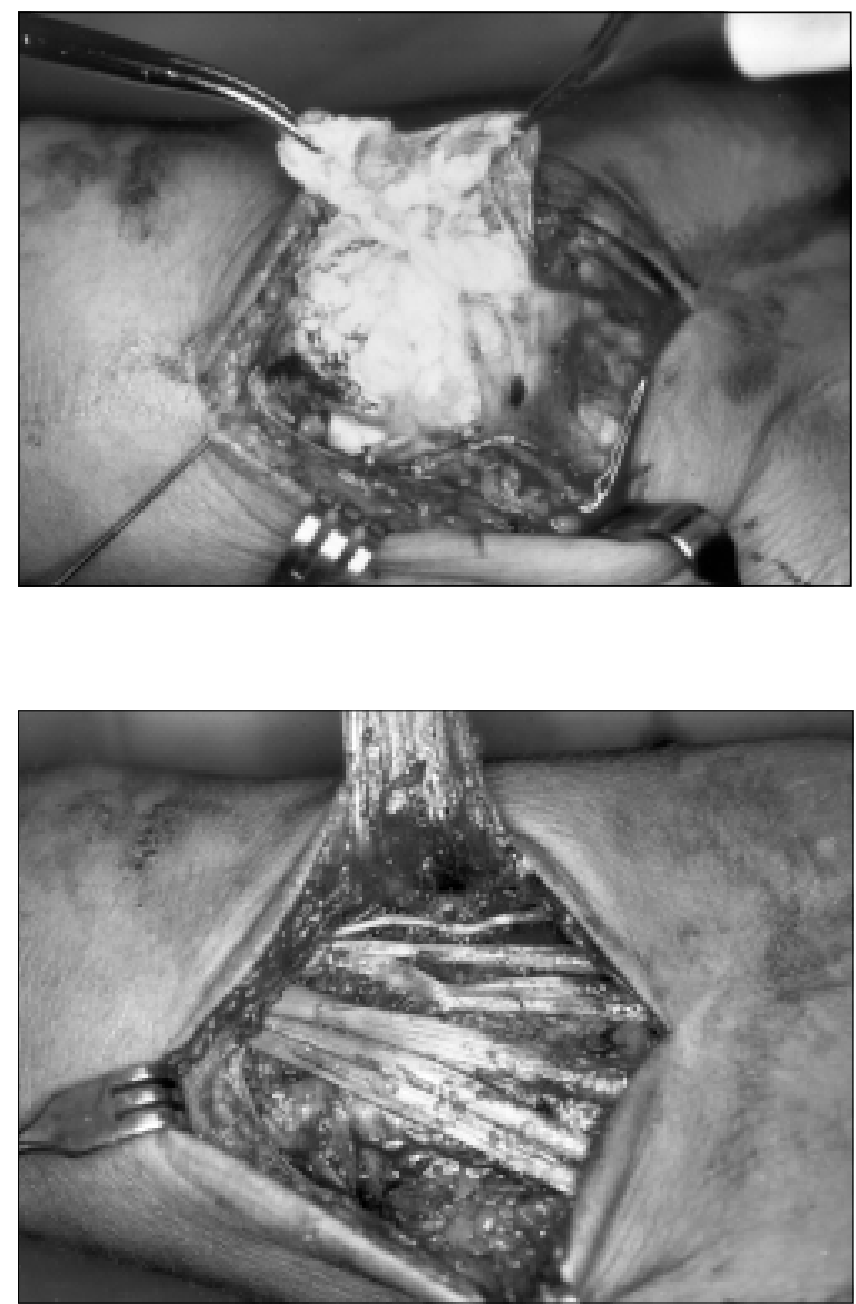

Figure 3) Top left The calcium mass under the extensor synovial hood. Top right Reflecting the synovial hood. Note the close adherence of the deposits. Bottom left The texture of the calcium was crystalline and incorporated throughout the extensor tendons. Bottom right Excision of the calcium

pain became excruciating and debilitating. Despite splinting, elevation and intravenous morphine for analgesia, the symptoms progressed, the discomfort was uncontrolled and the patient became markedly depressed. The left hand was erythematous and moderately swollen. The skin was shiny and lacked hair on the dorsum (Figure 1). The fingers were in a resting position of $40^{\circ}$ of metacarpal phalangeal flexion (MCP), $50^{\circ}$ proximal interphalangeal (PIP) flexion 


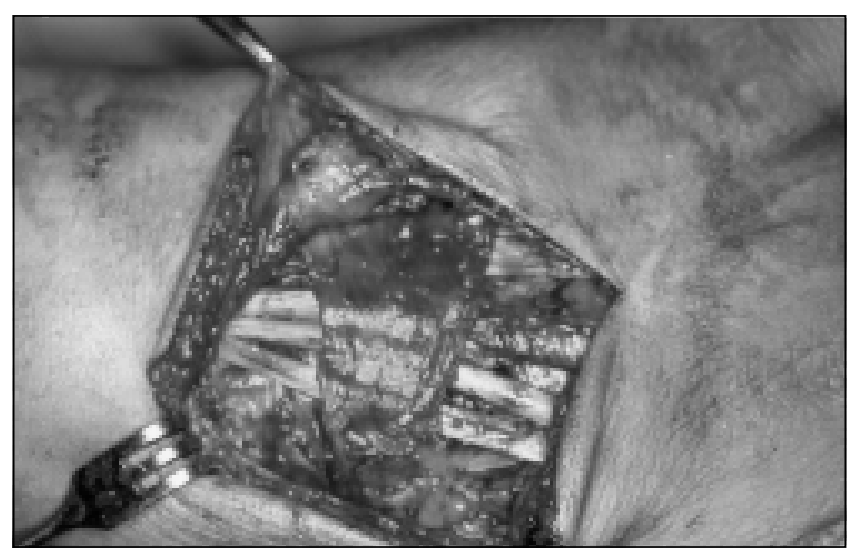

Figure 4) The synovial hood was draped back over the extensor tendons

and $15^{\circ}$ distal interphalangeal flexion. There was a firm, tender, immobile mass present on the dorsum of the left hand. The index finger was nontender, fusiform and boggy to palpate, and notably fluctuant proximally. A nontender, moderately mobile mass was present in the first web space. Flexion of the fingers was markedly diminished with demonstrable extensor tendon tethering. There was a $15^{\circ}$ extension lag to all digits at the MCP joints. Radiographs revealed opacities on the dorsum of the left hand, the digits, first web space and thumb (Figure 2). Surgical extirpation of the calcium deposits on the dorsum of the left hand and index finger was performed. The calcium was intimately associated with eroding into the extensor tendons of the fourth compartment (Figure 3). This calcific tenosynovitis had a thick, viscous, pasty nature with some areas of crystallized calcium from the encased digit. There was no extension proximally under the retinaculum. Following this complete evacuation, the index finger was milked to squeeze the calcium from the encased digit (Figure 4). The material was a viscous liquid (paste) expressed mostly from the dorsoradical aspect of the finger. Hemostasis was secured, the wounds closed and range of motion exercises were initiated immediately. Postoperatively, the wounds healed uneventfully and the pain resolved completely within one week. Full range of motion was observed at three weeks postoperatively. Nine months after surgery, the patient complained of increasing pain to the left first web space thumb and dorsum of the hand. Uncontrolled progressive pain necessitated a second operation for the removal of further calcium (Figure 5). Viscous and coarse deposits were observed. A minimal amount of pasty material was removed from the dorsum of the hand between the extensor tendons. The second postoperative course was similar to the initial surgery. The patient has remained pain-free two years after surgery.

\section{DISCUSSION}

Scleroderma is an autoimmune disorder of the connective tissue that is often associated with soft tissue calcifications (3). There are varying presentations of scleroderma includ-

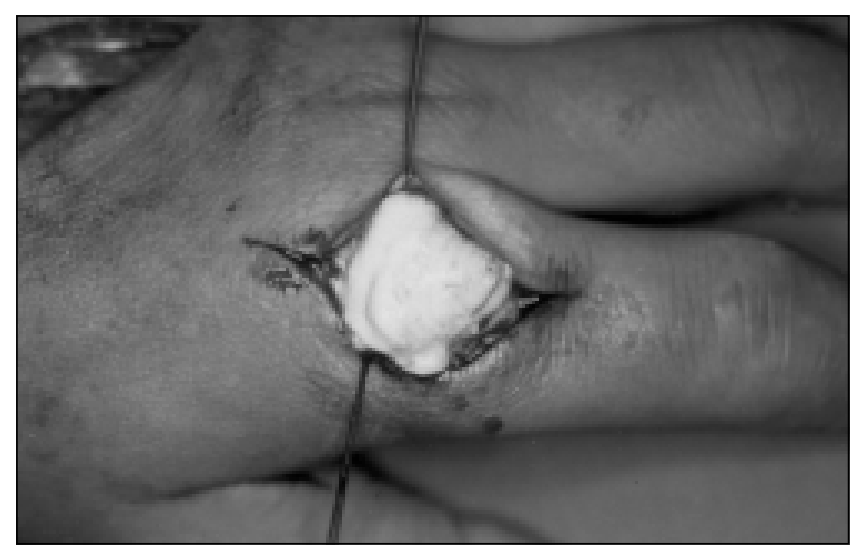

Figure 5) Calcium released from the subcutaneous plane at the metacarpal phalangeal joint of the index finger. This deposit is pasty and extends to the dorsum of the finger to the proximal interphalangeal level

ing systemic, local, linear and morpheic types $(3,4)$. The CREST syndrome is most likely to manifest in the systemic form of scleroderma. An increase in the fibroblast production of collagen in skin, other organs and viscera promote a varied clinical presentation. Small vessel disease results from primary endothelial damage of unknown etiology. Platelet aggregation and myointimal proliferation and fibrosis end in lumen obliteration. Altered permeability leads to interstitial edema and fibrosis. Ultimately, the absolute number of capillaries and vessels diminish, while other capillaries may dilate and become ectatic producing telangiectasia (3). This produces the characteristic nonwrinkled, shiny, edematous appearance of the skin. Laboratory investigations for anticentromere antibodies, flourescent antinuclear antibodies, antiRNA polymerase 1 or anti-SCL-70 may aid in the diagnosis. The medical management is limited although steroids, antiinflammatories, D-peniciliamine, calcium channel blockers and possibly plasmapheresis have had some success in curtailing the disorder $(3,4,5)$.

Surgical involvement of patients with scleroderma is not common. In the hand, scleroderma can manifest as digital tip ulceration and ischemia, Raynaud's phenomenon, flexor contractures at the PIP and MCP joints, erosion of the proximal phalanx dorsally at the PIP, focal entrapment neuropathy, and intracutaneous and subcutaneous calcinosis $(1,2,5-7)$. Tissue calcinosis can be of the dystrophic or heterotopic forms (8). The calcifications of scleroderma are possibly a combination of both forms. The deposits in viable tissue of unknown etiology are heterotopic calcifications. Those that are within degenerative or nonviable tissue (as in areas of severe fibrosis or fat necrosis) are considered dystrophic calcifications. The calcinosis in the scleroderma hand is typically found on the volar aspect of the digits and dorsum of the hand. The deposition of calcium can be of a 'toothpaste' consistency, a firm crystalline form or a mixture of either end of this spectrum. The crystalline form may incite a greater local reaction, or erode through the skin (observed at ulcera- 
tion sites) or into local soft tissues such as synovium, tendon or capsule. Coarse deposits may indicate a more chronic deposition whereas the more 'pasty' calcium may be more acute. The deposits are composed of calcium carbonate and calcium phosphate, and varied cellular infiltrate $(9,10,11)$. Imbalances of the calcium, phosphorous and the associated regulatory hormones have not been identified and, therefore, the exact etiology of the calcinosis in scleroderma is unknown.

\section{CONCLUSIONS}

We reported a case of calcinosis involving the digits and dorsum of the hand. The deposition of the calcium not only invaded the extensor tendons, thereby inciting a calcific synovitis, but was also severely debilitating because of the

\section{REFERENCES}

1. Jones NF, lmbrigila JE, Steen VD, Medsger TA. Surgery for scleroderma of the hand. J Hand Surg [Am] 1987;12:391-400.

2. Idler RS, Strickland JW, Creighton JJ. Scleroderma and its manifestations in the hand. Indiana Med 1991;84:702-3.

3. Medsger TA. Epidemiology of systemic sclerosis. Clin Dermatol 1994;12:207-16.

4. Nishikai M, Itoh K, Sato A. Calcinosis and the anticentomere antibody: its clinical, radiological and immunogenetic aspects. Br J Rheumatol 1992;31:9-12.

5. Farah MJ, Palmieri GM, Sebes JL, et al. The effect of diltiazem on calcinosis in a patient with the Crest syndrome. Arthritis Rheum 1990;33:1287-93.

6. Thurman RT, Jindal P, Wolff TW. Ulnar nerve compression in Guyon's canal caused by calcinosis in scleroderma. J Hand Surg [Am] 1991;6:739-41. pain it caused. The mass effect on the dorsum impeded tendon excursion, limiting flexion and extension of the digits. This is not an uncommon finding, but the extent of involvement was unusual. In fact, there is little in the literature observing extreme degrees of discomfort with the calcinosis associated with scleroderma. Since this time, the patient has had acute episodes of painful calcinosis requiring the removal of further calcium depositions. Calcific ulcers, PIP dorsal erosion and joint contractures have necessitated corrective surgery. Attempts at digital revascularization and digital sympathectomy have shown promise in curtailing the ongoing Raynaud's phenomenon and distal ischemic changes $(12,13)$. Uncommonly, excision of the calcinosis has been warranted due to pain, nerve entrapment or impedance of motion. It is difficult to remove all of the local calcium deposit and recurrence is likely, however, this should not deter from surgical removal if the symptoms are severe.

7. Polio JL, Stern PJ. Digital nerve calcification in CREST syndrome. J Hand Surg [Am] 1989;14:201-3.

8. Hussmann J, Russell RC, Kucan JO, Khardori R, Steinau HU. Soft-tissue Calcifications: differential diagnosis and therapeutic approaches. Ann Plast Surg 1995;4:138-47.

9. Buschmann WR, Myers W, Sager G. Tumoral Calcinosis. Case presentation and review. Orthop Rev 1989;18:440-2.

10. Viegas SF, Evans EB, Calhoun J, Goodwiller SE. Tumoral calcinosis: a case report and review of the literature. J Hand Surg [Am] 1985;10:744-8.

11. Fam AG, Pritzker KP. Acute calcific periarthritis in scleroderma. Rheumatology 1992;19:1580-5.

12. O'Brien BM, Kumar PAV, Mellow CG, Oliver TV. Radical microarteriolysis in the treatment of vasospastic disorders of the hand, especially scleroderma. J Hand Surg [Br] 1992;17:447-52.

13. Jones NF, Raynor SC, Medsger TA. Microsurgical revascularization of the hand in scleroderma. Br J Plast Surg 1987;40:264-9. 